\title{
TRIGONOMETRIC APPROXIMATION OF FUNCTIONS IN SEMINORMED SPACES
}

\author{
WŁODZIMIERZ ŁENSKI, UADAY SINGH* AND BOGDAN SZAL
}

Abstract. In this paper, we study the approximation properties of $2 \pi$-periodic functions in a seminormed space. We use a general matrix method of summability, and the moduli of continuity in the seminormed space as a measure of approximation. Our results generalize and improve some of the previous results available in the literature.

Mathematics subject classification (2010): 41A25, 46E30, 42A24, 42A10, 40C05.

Keywords and phrases: Seminorm, rate of approximation, the Jensen inequality, Fourier series, matrix means.

\section{REFERENCES}

[1] P. ChandRa, Trigonometric approximation of functions in $L_{p}$-norm, J. Math. Anal. Appl., 275 (2002), 13-26.

[2] A. GuVEn, Trigonometric approximation in reflexive Orlicz spaces, Anal. Theory Appl., 27 (2) (2011), 125-137.

[3] A. Guven, D. M. IsRAfilov, Approximation by trigonometric polynomials in weighted Orlicz spaces, Stud. Math., 174 (2006), 147-168.

[4] A. Guven, D. M. IsRAFILOv, Improved inverse theorems in weighted Lebesgue and Smirnov spaces, Bull. Belg. Math. Soc., 14 (2007), 681-692.

[5] L. LEINDLER, On the uniform convergence and boundedness of a certain class of sine series, Analysis Math., 27 (2001), 279-285.

[6] L. LeINDLER, On the degree of approximation of continuous functions, Acta Math. Hungar., 104 (2004), 105-113.

[7] L. LeIndLER, Trigonometric approximation in $L_{p}$-norm, J. Math. Anal. Appl., 302 (1) (2005), 129 136.

[8] E. Liflyand, S. TikHonov, A concept of general monotonicity and applications, Math. Nachr., 284 (8-9) (2011), 1083-1098.

[9] U. S. PugacheV, I. N. Sinitsy, Lectures on functional analysis and applications, Word Scientific Publ. (1999).

[10] R. N, Mohapatra, B. SzaL, On trigonometric approximation of functions in the $L^{q}$ norm, Demonstratio Mathematica, 51 (1) (2018), 17-26

[11] B. SzAL, Trigonometric approximation by Nörlund type means in $L^{p}$-norm, Comm. Math. Universitatis Carolinae, 50 (4) (2009), 575-589.

[12] S. TikHonov, Trigonometric series with general monotone coefficients, J. Math. Anal. Appl., 326 (1) (2007), 721-735.

[13] S. TikHonov, On uniform convergence of trigonometric series, Mat. Zametki, 81 (2) (2007), 304 310, Translation in Math. Notes, 81 (2) (2007), 268-274.

[14] S. Tikhonov, Best approximation and moduli of smoothness: Computation and equivalence theorems, J. Approx. Theory, 153 (2008), 19-39.

[15] D. S. YU, S. P. ZHOU, A generalization of monotonicity and applications, Acta Math. Hungar., 115 (3) (2007), 247-267.

[16] D. S. YU, S. P. ZHOU, P. ZHOU, Ultimate generalization to monotonicity for uniform convergence of trigonometric series, Sci. China Math., 53 (7) (2010), 1853-1862. 
[17] V. V. ZHUK, Approximation of periodic functions, (in Russian), Leningr. Gos. Univ. Press, Leningrad, (1982).

[18] A. Zygmund, Trigonometric Series, Vol I, Cambridge Univ. Press, 2nd edition, (1959). 